\title{
Solution Methods for Linear Factorized Quadratic Optimization and Quadratic Fractional Optimization Problem
}

\author{
K. C. Sharma*, Jitendra Singh ${ }^{* *}$ \\ *(Department of Mathematics, Govt. M. S. J. College Bharatpur (RAJ.) India) \\ **: (Department of Mathematics, Govt. College Baran (RAJ.) India)
}

\begin{abstract}
In this paper, we use new approach for linear factorized quadratic optimization and a quadratic fractional optimization problem. We observed that there is change in the rule of selecting entering vector at initial stage and for some quadratic optimization problem; it takes more number of iteration to achieve optimality. Here at the initial step we choose the entering vector on the basis of new rules of method described below. Like a linear fractional programming problem (LFPP), linear factorized quadratic optimization problem (LFQOP) and quadratic fractional optimization problem (LFQFOP) can be usefully applied in a wide range of real-world applications. These are useful in solving the problem in economics whenever the different economic activities utilize the fixed resources in proportion to the level of their values, hospital and health care planning, financial planning etc. In the last few decades a lot of research papers and monographs were published throughout the world where authors investigated different theoretical and algorithmic aspects of QOP and QFO problems in various forms. Quadratic fractional program is an optimization problem wherein one either minimizes or maximizes a quadratic fractional objective function subject to finite number of linear inequality or equality constraints. In this paper, we propose solution methods for linear factorized quadratic optimization problem and factorized quadratic fractional optimization problem with new approach.
\end{abstract}

Keywords: Optimality Conditions, LFQOP, LFQFOP, Simplex Technique.

\section{Introduction}

In this paper, we consider the following fractional programming problem:

$$
\operatorname{Maximize} \Phi(\mathrm{x})=\frac{\mathrm{f}(\mathrm{x})}{\mathrm{g}(\mathrm{x})}, \forall \mathrm{x} \in \mathrm{S}
$$

where $\mathrm{S}=\left\{\mathrm{x} \in \mathrm{R}^{\mathrm{n}}: \mathrm{Ax} \leq \mathrm{b}\right\}$ and $\mathrm{g}(\mathrm{x})>0$ on $\mathrm{S}$.

Problem (1) has many applications in economics and engineering. For instance, problems such as minimization of average cost function and maximization of consumption per a capital belong to class of fractional programming.

Nature of fractional programming is depending on type of functions $\mathrm{f}(\mathrm{x})$ and $\mathrm{g}(\mathrm{x})$ and classification of problem (1) is as follows:

$>$ Fractional programming (1) is called a linear fractional optimization problem if all functions $\mathrm{f}(\mathrm{x})$ and $\mathrm{g}(\mathrm{x})$ are affine;

$>$ Fractional programming (1) is said to be a linear factorized quadratic fractional optimization problem if both $\mathrm{f}(\mathrm{x})$ and $\mathrm{g}(\mathrm{x})$ are linear factorized quadratic functions;

$>$ Fractional programming (1) is said to be a linear factorized quadratic optimization problem if $\mathrm{f}(\mathrm{x})$ is linear factorized quadratic functions and $\mathrm{g}(\mathrm{x})=1$.

$>$ Fractional programming (1) is called a concave-convex fractional optimization program if $\mathrm{f}(\mathrm{x})$ is concave and $\mathrm{g}(\mathrm{x})$ is convex;

In the Proposal problem (1), the objective function of linear factorized quadratic optimization has a product of two positive linear functions. Sharma S.D. [6] gives a simplex method and Hasan M.B. [3] presented a technique for this type problem. Now, we use new approach by change the rule of selecting entering vector at the initial stage for linear factorized quadratic optimization. In the problem (1), the objective function of linear factorized quadratic fractional optimization problems has ratio of two quadratic objectives that have linear factorized numerator and denominator. There were several results on fractional programming (1). R. Enkhabat and etc. all [5] gives a method for fractional programming. Fukushima M. and etc. all [2] studies on quadratic fractional programming problems with quadratic constraints. More recently Abdulrahim B.K. [1] worked on quadratic fractional programming problem via feasible direction development and suggested modified simplex method for this problem and we use new approach by change the rule of selecting entering vector at initial stage 
in this method. Khobragade [4] gives an alternate approach to Wolfe's modified simplex method for quadratic programming problem. During this paper we use this approach for linear factorized quadratic optimization problem and quadratic fractional optimization problem and order to extend this work, we propose solution methods which are exactly similar to simplex technique in linear programming and finally we have showed some numerical results of the techniques.

\section{Some Important Basic Concepts Related To This Work}

\section{Linear Factorized Quadratic Optimization Problem (LFQOP):}

Consider a quadratic optimization problem in which the objective function can be written as the product of two linear functions in the following format:

$$
\left.\begin{array}{c}
\text { Maximize } f(x)=\frac{1}{2} x^{T} Q x+c^{T} x+d=\left(c_{1}{ }^{T} x+\alpha\right)\left(c_{2}{ }^{T}+\beta\right)=f_{1}(x) \cdot f_{2}(x) \\
\text { s. t. } \quad A x \leq b \\
\quad x \geq 0
\end{array}\right\}
$$

Where $\mathrm{x}^{\mathrm{T}}, \mathrm{c}, \mathrm{c}_{1}, \mathrm{c}_{2} \in \mathrm{R}^{\mathrm{n}}, \mathrm{b}^{\mathrm{T}} \in \mathrm{R}^{\mathrm{m}}, \mathrm{d}, \alpha, \beta \in \mathrm{R}, \mathrm{Q}$ be a symmetric $\mathrm{n} \mathrm{x}$ m matrix and $\mathrm{A}$ is $\mathrm{m} \mathrm{x} \mathrm{n}$ matrix.

\section{Linear Factorized Quadratic Fractional Optimization Problem (LFQFOP):}

In this study we have a FQFOP in the following format:

$$
\begin{gathered}
\text { Maximize } \Phi(x)=\frac{f(x)}{g(x)}=\left(c_{1}{ }^{T} x+\alpha\right)\left(c_{2}{ }^{T} x+\beta\right) /\left(c_{3}{ }^{T} x+\gamma\right)\left(c_{4}{ }^{T} x+\delta\right), \\
A x \leq b \\
x \geq 0
\end{gathered}
$$

Where $A$ is $m x$ matrix $b \in R^{m}, c_{1}, c_{2}, c_{3}, c_{4} \in R^{n}, \alpha, \beta, \gamma, \delta \in R$ and $f(x)=\left(c_{1}{ }^{T} x+\alpha\right)\left(c_{2}{ }^{T} x+\beta\right)$ and $g(x)=\left(c_{3}{ }^{T} x\right.$ $+\gamma)\left(c_{4}^{T} \mathrm{x}+\delta\right)$ are quasi concave quadratic function and here we assume that factors $\left(\mathrm{c}_{1}^{\mathrm{T}} \mathrm{x}+\alpha\right),\left(\mathrm{c}_{2}^{\mathrm{T}} \mathrm{x}+\beta\right),\left(\mathrm{c}_{3}{ }^{\mathrm{T}} \mathrm{x}\right.$ $+\gamma)$ and $\left(\mathrm{c}_{4}{ }^{\mathrm{T}} \mathrm{x}+\delta\right)$ are positive for all feasible solution and constraints set $\mathrm{S}=\left\{\mathrm{x} \in \mathrm{R}^{\mathrm{n}}: \mathrm{Ax} \leq \mathrm{b}, \mathrm{x} \geq 0\right\}$ of feasible solution is nonempty and bounded .

$$
\begin{gathered}
\text { If } \mathrm{f}_{1}(\mathrm{x})=\mathrm{c}_{1}{ }^{\mathrm{T}} \mathrm{x}+\alpha, \mathrm{f}_{2}(\mathrm{x})=\mathrm{c}_{2}{ }^{\mathrm{T}} \mathrm{x}+\beta, \mathrm{g}_{1}(\mathrm{x})=\mathrm{c}_{3}{ }^{\mathrm{T}} \mathrm{x}+\gamma \text { and } \mathrm{g}_{2}(\mathrm{x})=\mathrm{c}_{4}{ }^{\mathrm{T}} \mathrm{x}+\delta \text { then equation (3) can we written as } \\
\text { Maximize } \Phi(\mathrm{x})=\frac{\mathrm{f}(\mathrm{x})}{\mathrm{g}(\mathrm{x})}=\mathrm{f}_{1}(\mathrm{x}) \cdot \mathrm{f}_{2}(\mathrm{x}) / \mathrm{g}_{1}(\mathrm{x}) \cdot \mathrm{g}_{2}(\mathrm{x})
\end{gathered}
$$

\section{The Simplex Technique}

The simplex technique is a systematic procedure for solving mainly LLP. The technique moves from one extreme point to another, with a smaller value for the objective function $f(\mathbf{x})$. In iterative procedure, some of the inequality constraints are forced to be temporarily binding, its means that the left-hand side of the constraint is equal to the right-hand side of the constraint. The indices of these constraints are referred to as the active set. To obtain the solution for a problem, the first step of the techniques is to obtain an initial feasible solution and an active set containing the constraints satisfying that feasible solution. The feasible solution is then checked for optimality. If the feasible solution is not the optimal solution (in this case maximum), then an optimal solution can still be reached, or it can be shown that the objective function can be made arbitrarily greatest, by changing the constraints in the active set one at a time. The active set is changed by removing one of the constraints and selecting another constraint to come into the active set provided that the constraint will become binding. Since each change of a constraint in an active set decreases the value of the objective function, no active set can be repeated. If an active set should repeat, then the objective function would not decrease, which results in a contradiction. As no active set can ever be repeated, the solution will be obtained in a finite number of steps.

Definition (Basic Feasible Solution): given a system of $m$ simultaneous linear in $n$ unknowns $(m<n)$

$$
\mathrm{Ax}=\mathrm{b}, \quad \mathrm{x}^{\mathrm{T}} \in \mathrm{R}^{\mathrm{n}}
$$


Where $A \in R^{\mathrm{mxn}}$ matrix of rank $m$. let $B$ be any sub matrix, formed by $m$ linearly independent columns of $A$. then a solution obtained by setting $n-m$ variables (not associated with the columns of $B$ ) are equal to zero, and solving this system, is called a basic solution to the given system of equations and if it is feasible solution then this solution called basic feasible solution.

Theorem (Conditions of Optimality): A necessary and sufficient condition for a basic feasible solution to given problem to be an optimum (maximum) is that $\delta_{\mathrm{j}} \geq 0$ (for problem 2) and $\rho_{\mathrm{j}} \geq 0$ (for problem 3 ) for all which $\mathrm{j} \notin \mathrm{B}$ (basis).

Remark: Simplex technique is based on following two fundamental conditions:

$>$ Condition of feasibility.

$>$ Condition of optimality.

\section{Solution Methods}

Solution Method for Linear Factorized Quadratic Optimization Problem:

Consider a linear factorized quadratic optimization problem in the following format:

$\operatorname{Maximize} \Phi(x)=\left(c_{1 j}^{T} x+\alpha\right)\left(c_{2 j}^{T} x+\beta\right)=f_{1}(x) \cdot f_{2}(x)$

$$
\text { s.t. } A x \leq b \text {, }
$$

Where $\mathrm{x}^{\mathrm{T}}, \mathrm{c}_{1 \mathrm{j}}, \mathrm{c}_{2 \mathrm{j}} \in \mathrm{R}^{\mathrm{n}}, \mathrm{b}^{\mathrm{T}} \in \mathrm{R}^{\mathrm{m}}, \alpha, \beta \in \mathrm{R}, \mathrm{Q}$ be a symmetric $\mathrm{n} \mathrm{x} \mathrm{n}$ matrix and $\mathrm{A}$ is $\mathrm{m} \mathrm{x} \mathrm{n}$ matrix.

This problem has following steps for proposal approach

Step1. If the given problem is not in the standard form then we convert in this form by introducing slack and surplus variables and convert inequalities to equations.

Step2. To finds the initial basic feasible solution $x_{B}=B^{-1} b$ of the problem (4).

Step3. Prepared the initial iteration by computing the following data which are necessary to simplex routine technique:

$$
\begin{aligned}
& \mathrm{f}_{1}(\mathrm{x})=\mathrm{c}_{\mathrm{B} 1} \mathrm{x}_{\mathrm{B}}+\alpha, \mathrm{f}_{2}(\mathrm{x})=\mathrm{c}_{\mathrm{B} 2} \mathrm{x}_{\mathrm{B}}+\beta \\
& \therefore \Phi(\mathrm{x})=\mathrm{f}_{1}(\mathrm{x}) \cdot \mathrm{f}_{2}(\mathrm{x}) \\
& \Delta \mathrm{l}_{1}{ }^{1 \mathrm{j}}=\mathrm{c}_{\mathrm{B} 1} \mathrm{x}_{\mathrm{j}}-\mathrm{c}_{1 \mathrm{j}}, \quad \Delta \mathrm{l}_{1}{ }^{2 \mathrm{j}}=\mathrm{c}_{\mathrm{B} 2} \mathrm{x}_{\mathrm{j}}-\mathrm{c}_{2 \mathrm{j}}, \quad \mathrm{j}=1,2, \ldots ., \mathrm{m}+\mathrm{n},
\end{aligned}
$$

We also compute $\mu_{\mathrm{j}}=\min \left(\mathrm{x}_{\mathrm{B}} / \mathrm{x}_{\mathrm{j}}\right)$ for non-basic variables

Minimum ratio $=\min \left(\mathrm{x}_{\mathrm{Bi}} / \mathrm{x}_{\mathrm{ir}}, \mathrm{x}_{\mathrm{ir}}>0\right)$ for outgoing vector

Finally we find out:

For problem (4)

$$
\left\{\begin{array}{l}
\delta_{\mathrm{j}}=\mathrm{f}_{2}(\mathrm{x}) \Delta \mathrm{l}_{1}{ }^{1 \mathrm{j}}+\mathrm{f}_{1}(\mathrm{x}) \Delta \mathrm{l}_{1}{ }^{2 \mathrm{j}}-\mu_{\mathrm{j}} \Delta \mathrm{l}_{1}{ }^{1 \mathrm{j}} \Delta \mathrm{l}_{1}{ }^{2 \mathrm{j}} \\
\Omega_{2 \mathrm{j}}=\frac{\delta \mathrm{j}}{\sum \mathrm{xi}} \quad \begin{array}{l}
\sum \mathrm{x}_{\mathrm{i}}>0, \text { where } \sum \mathrm{x}_{I}(>0) \text { is the sum of basic variables in running } \\
\text { iterative table to the corresponding column. }
\end{array}
\end{array}\right.
$$

In the every iteration, $c_{1 j}$ and $c_{2 j}$ are the coefficients of the basic and non basic variables and $c_{B 1}$ and $c_{B 2}$ are the coefficients of the basic variables in the objective function of the above problem (4).

Step4. Obtain an optimal solution of the problem in above mentioned rules by using new technique for determine the basic vector by choosing most negative value of $\Omega_{2 j}$ (defined as above) and corresponding vector will enter into the basic and Minimum ratio $=\min \left(\mathrm{x}_{\mathrm{Bi}} / \mathrm{x}_{\mathrm{ir}}, \mathrm{x}_{\mathrm{ir}}>0\right)$ for outgoing vector in simplex processing.

Step5. If all $\delta_{j} \geq 0$ and $\Omega_{2 j} \geq 0$ then the optimum solution obtain and if not then go to step 4 and check the obtain solution for optimality. Thus the solution can be improved until all $\delta_{j} \geq 0$ and $\Omega_{2 j} \geq 0$ in simplex routine, the solution become optimal and process terminates. 
Numerical example (1) [Hasan, 2012]

Maximize $\Phi(\mathrm{x})=\left(2 \mathrm{x}_{1}+4 \mathrm{x}_{2}+\mathrm{x}_{3}+1\right)\left(\mathrm{x}_{1}+\mathrm{x}_{2}+2 \mathrm{x}_{3}+2\right)$

$$
\begin{array}{ll}
\text { s. t. } & \mathrm{x}_{1}+3 \mathrm{x}_{2} \leq 4, \\
& 2 \mathrm{x}_{1}+\mathrm{x}_{2} \leq 3, \\
& \mathrm{x}_{2}+4 \mathrm{x}_{3} \leq 3, \\
& \mathrm{x}_{1}, \mathrm{x}_{2}, \mathrm{x}_{3} \geq 0
\end{array}
$$

Step1 \& Step2. Convert the inequality constraints into equations by adding slack variables $\mathrm{x}_{4}, \mathrm{x}_{5}$ and $\mathrm{x}_{6}$ resp.

\begin{tabular}{|c|c|c|c|c|c|c|c|c|c|c|}
\hline & & & $\mathrm{c}_{1 \mathrm{j}}$ & 2 & 4 & 1 & 0 & 0 & 0 & \\
\hline \multicolumn{3}{|l|}{ Iteration .1 } & $\mathrm{c}_{2 \mathrm{j}}$ & 1 & 1 & 2 & 0 & 0 & 0 & \multirow{2}{*}{$\begin{array}{l}\text { Min. } \\
\text { ratio }\end{array}$} \\
\hline $\begin{array}{c}\text { Basic } \\
\text { variables }\end{array}$ & $\mathrm{c}_{\mathrm{B} 1}$ & $\mathrm{c}_{\mathrm{B} 2}$ & $\mathrm{x}_{\mathrm{B}}$ & $\mathrm{x}_{1}$ & $\mathrm{x}_{2}$ & $\mathrm{x}_{3}$ & $\mathrm{x}_{4}$ & $\mathrm{x}_{5}$ & $\mathrm{x}_{6}$ & \\
\hline $\mathrm{x}_{4}$ & 0 & 0 & 4 & 1 & 3 & 0 & 1 & 0 & 0 & $4 / 3-$ \\
\hline $\mathrm{X}_{5}$ & 0 & 0 & 3 & 2 & 1 & 0 & 0 & 1 & 0 & 3 \\
\hline $\mathrm{x}_{6}$ & 0 & 0 & 3 & 0 & 1 & 4 & 0 & 0 & 1 & 3 \\
\hline \multirow{3}{*}{\multicolumn{3}{|c|}{$\begin{array}{c}f_{1}(x)=c_{B 1} x_{B}+\alpha=1 \\
f_{2}(x)=c_{B 2} x_{B}+\beta=2\end{array}$}} & $\Delta l_{l}^{1 \mathrm{j}}$ & -2 & -4 & -1 & 0 & 0 & 0 & \multirow{4}{*}{$\begin{array}{l}\alpha=1 \\
\beta=2\end{array}$} \\
\hline & & & $\Delta l_{l}^{2 \mathrm{j}}$ & -1 & -1 & -2 & 0 & 0 & 0 & \\
\hline & & & $\delta_{\mathrm{j}}$ & -8 & $-43 / 3$ & $-11 / 2$ & 0 & 0 & 0 & \\
\hline \multicolumn{3}{|c|}{$\Phi=f_{1}(x) \cdot f_{2}(x)=2$} & $\Omega_{2 \mathrm{j}}$ & $-8 / 3$ & $-43 / 15 \mathbf{A}$ & $-11 / 8$ & - & - & - & \\
\hline \multicolumn{11}{|c|}{$\begin{array}{l}\text { From the above iteration, it is apparent that there are three } \Omega_{2 \mathrm{j}} \text { which are negative. According to our new approach, we choose the most } \\
\text { negative of these, viz., -43/15. The corresponding column vector } \mathrm{x}_{2} \text { enter the basis and minimum ratio is } 4 / 3 \text { then corresponding vector } \\
\mathrm{x}_{4} \text { will leave the basis } \mathrm{x}_{\mathrm{B}} \text {. Feasible solution } \mathrm{x}_{1}=0, \mathrm{x}_{2}=0, \mathrm{x}_{3}=0, \mathrm{x}_{4}=4, \mathrm{x}_{5}=3, \mathrm{x}_{6}=3 \text { and max } z=2 \text { this solution is not optimal solution } \\
\text { because all } \delta_{j} \geq 0 \text { and } \Omega_{2 j} \geq 0 \text {. Thus the solution can be improved until all } \delta_{j} \geq 0 \text { and obtain optimal solution of our problem. } \\
\text { Iteration } 2\end{array}$} \\
\hline $\mathrm{x}_{2}$ & 4 & 1 & $4 / 3$ & $1 / 3$ & 1 & 0 & $1 / 3$ & 0 & 0 & - \\
\hline $\mathrm{x}_{5}$ & 0 & 0 & $5 / 3$ & $5 / 3$ & 0 & 0 & $-1 / 3$ & 1 & 0 & - \\
\hline $\mathrm{x}_{6}$ & 0 & 0 & $5 / 3$ & $-1 / 3$ & 0 & 4 & $-1 / 3$ & 0 & 1 & $5 / 12$ \\
\hline \multirow{2}{*}{\multicolumn{3}{|c|}{$\begin{array}{c}\mathrm{f}_{1}(\mathrm{x})=\mathrm{c}_{\mathrm{B} 1} \mathrm{x}_{\mathrm{B}}+\alpha=19 / 3 \\
\mathrm{f}_{2}(\mathrm{x})=\mathrm{c}_{\mathrm{B} 2} \mathrm{x}_{\mathrm{B}}+\beta=10 / 3\end{array}$}} & $\Delta l_{l}{ }^{\mathrm{Ij}}$ & $-2 / 3$ & 0 & -1 & $4 / 3$ & 0 & 0 & \multirow{2}{*}{$\begin{array}{l}\alpha=1 \\
\beta=2\end{array}$} \\
\hline & & & $\Delta l_{l}^{2 \mathrm{j}}$ & $-2 / 3$ & 0 & -2 & $1 / 3$ & 0 & 0 & \\
\hline \multirow{2}{*}{\multicolumn{3}{|c|}{$\Phi=\mathrm{f}_{1}(\mathrm{x}) \cdot \mathrm{f}_{2}(\mathrm{x})=190 / 9$}} & $\delta_{\mathrm{j}}$ & $-62 / 9$ & 0 & $-101 / 6$ & $43 / 9$ & 0 & 0 & \\
\hline & & & $\Omega_{2 \mathrm{j}}$ & $-69 / 15$ & 0 & $\begin{array}{c}-101 / 24 \\
4\end{array}$ & - & - & - & \\
\hline \multicolumn{3}{|l|}{ Iteration 3} & & & & & & & & \\
\hline $\mathrm{x}_{2}$ & 4 & 1 & $4 / 3$ & $1 / 3$ & 1 & 0 & $1 / 3$ & 0 & 0 & 4 \\
\hline $\mathrm{X}_{5}$ & 0 & 0 & $5 / 3$ & $5 / 3$ & 0 & 0 & $-1 / 3$ & 1 & 0 & 1 \\
\hline $\mathrm{x}_{3}$ & 1 & 2 & $5 / 12$ & $-1 / 12$ & 0 & 1 & $-1 / 12$ & 0 & $1 / 4$ & \\
\hline \multirow{3}{*}{\multicolumn{3}{|c|}{$\begin{array}{c}\mathrm{f}_{1}(\mathrm{x})=\mathrm{c}_{\mathrm{B} 1} \mathrm{x}_{\mathrm{B}}+\alpha=27 / 4 \\
\mathrm{f}_{2}(\mathrm{x})=\mathrm{c}_{\mathrm{B} 2} \mathrm{x}_{\mathrm{B}}+\beta=25 / 6\end{array}$}} & $\Delta l_{I}^{1 \mathrm{j}}$ & $-3 / 4$ & 0 & 0 & $5 / 4$ & 0 & $1 / 4$ & \multirow{4}{*}{$\begin{array}{l}\alpha=1 \\
\beta=2\end{array}$} \\
\hline & & & $\Delta l_{l}^{2 \mathrm{j}}$ & $-5 / 6$ & 0 & 0 & $1 / 6$ & 0 & $1 / 2$ & \\
\hline & & & $\delta_{\mathrm{j}}$ & $-75 / 8$ & 0 & 0 & $11 / 2$ & 0 & $101 / 24$ & \\
\hline$\Phi=\mathrm{f}_{1}$ & $\mathrm{f}_{2}(\mathrm{x})$ & & $\Omega_{2 \mathrm{j}}$ & $\Delta-225 / 23$ & - & - & - & - & $101 / 6$ & \\
\hline \multicolumn{11}{|l|}{ Iteration 4} \\
\hline $\begin{array}{c}\text { Basic } \\
\text { variables }\end{array}$ & $\mathrm{c}_{\mathrm{B} 1}$ & $\mathrm{c}_{\mathrm{B} 2}$ & $\mathrm{X}_{\mathrm{B}}$ & $\mathrm{x}_{1}$ & $\mathrm{x}_{2}$ & $\mathrm{x}_{3}$ & $\mathrm{X}_{4}$ & $\mathrm{X}_{5}$ & $\mathrm{x}_{6}$ & \\
\hline $\mathrm{x}_{2}$ & 4 & 1 & 1 & 0 & 1 & 0 & $2 / 5$ & $-1 / 5$ & 0 & \\
\hline $\mathrm{x}_{1}$ & 2 & 1 & 1 & 1 & 0 & 0 & $-1 / 5$ & $3 / 5$ & 0 & \\
\hline $\mathrm{x}_{3}$ & 1 & 2 & $1 / 2$ & 0 & 0 & 1 & $-1 / 10$ & $1 / 20$ & $1 / 4$ & \\
\hline \multirow{3}{*}{\multicolumn{3}{|c|}{$\begin{array}{c}\mathrm{f}_{1}(\mathrm{x})=\mathrm{c}_{\mathrm{B} 1} \mathrm{x}_{\mathrm{B}}+\alpha=15 / 2 \\
\mathrm{f}_{2}(\mathrm{x})=\mathrm{c}_{\mathrm{B} 2} \mathrm{x}_{\mathrm{B}}+\beta=5\end{array}$}} & $\Delta l_{l}^{1 \mathrm{j}}$ & 0 & 0 & 0 & $11 / 10$ & $9 / 20$ & $1 / 4$ & \multirow{4}{*}{$\begin{array}{l}\alpha=1 \\
\beta=2\end{array}$} \\
\hline & & & $\Delta l_{l}^{2 \mathrm{j}}$ & 0 & 0 & 0 & 0 & $1 / 2$ & $1 / 2$ & \\
\hline & & & $\delta_{\mathrm{j}}$ & - & - & - & $11 / 2$ & $45 / 8$ & $19 / 4$ & \\
\hline \multicolumn{3}{|c|}{$\Phi=f_{1}(x) \cdot f_{2}(x)=75 / 2$} & $\Omega_{2 \mathrm{j}}$ & - & - & - & 55 & $9 / 20$ & 19 & \\
\hline
\end{tabular}
and find out the following initial basic feasible solution:

$\mathrm{x}_{1}=\mathrm{x}_{2}=\mathrm{x}_{3}=0, \mathrm{x}_{4}=4, \mathrm{x}_{5}=3, \mathrm{x}_{6}=3$ and value of objective function is $=2$.

Step3. We construct following initial table by using the third step data of solution method.

Since all $\delta_{\mathrm{j}} \geq 0$ and $\Omega_{2 \mathrm{j}} \geq 0$ then the optimal solution has been reached. Thus, an optimum basic feasible solution to our problem is $\mathrm{x}_{1}=1, \mathrm{x}_{2}=1, \mathrm{x}_{3}=1 / 2$ and maximize $\Phi(\mathrm{x})=75 / 2$.

In the next method, we use same procedure for linear factorized quadratic fractional optimization with minor modification in step 3 of above solution method. 
Solution Method for Linear Factorized Quadratic Fractional Optimization Problem:

Consider the linear factorized quadratic optimization problem in the following format:

$\operatorname{Maximize} \Phi(x)=\frac{f(x)}{g(x)}=\left(c_{1 j}{ }^{T} x+\alpha\right)\left(c_{2 j}{ }^{T} x+\beta\right) /\left(c_{3 j}{ }^{T} x+\gamma\right)\left(c_{4 j}{ }^{T} x+\delta\right)$,

$$
\begin{gathered}
A x \leq b, \\
x \geq 0
\end{gathered}
$$

This problem has following steps for the proposal approach:

Step1. By introducing slack and surplus variables, first of all we convert inequalities to equations.

Step2. To finds the initial basic feasible solution $x_{B}=B^{-1} b$ of the problem (5).

Step3. Prepared the initial iteration by computing the following data which are necessary to simplex routine:

$\mathrm{f}_{1}(\mathrm{x})=\mathrm{c}_{\mathrm{B} 1} \mathrm{x}_{\mathrm{B}}+\alpha, \mathrm{f}_{2}(\mathrm{x})=\mathrm{c}_{\mathrm{B} 2} \mathrm{x}_{\mathrm{B}}+\beta, \mathrm{g}_{1}(\mathrm{x})=\mathrm{c}_{\mathrm{B} 3} \mathrm{x}_{\mathrm{B}}+\gamma$ and

$\mathrm{g}_{2}(\mathrm{x})=\mathrm{c}_{\mathrm{B} 4} \mathrm{x}_{\mathrm{B}}+\delta$

$\therefore \mathrm{f}(\mathrm{x})=\mathrm{f}_{1}(\mathrm{x}) \cdot \mathrm{f}_{2}(\mathrm{x}) \quad$ and $\mathrm{g}(\mathrm{x})=\mathrm{g}_{1}(\mathrm{x}) \cdot \mathrm{g}_{2}(\mathrm{x})$ then

$\Phi(\mathrm{x})=\frac{\mathrm{f}(\mathrm{x})}{\mathrm{g}(\mathrm{x})}$

$\Delta \mathrm{l}_{1}{ }^{1 \mathrm{j}}=\mathrm{c}_{\mathrm{B} 1} \mathrm{x}_{\mathrm{j}}-\mathrm{c}_{1 \mathrm{j}}, \quad \Delta \mathrm{l}_{1}{ }^{2 \mathrm{j}}=\mathrm{c}_{\mathrm{B} 2} \mathrm{x}_{\mathrm{j}}-\mathrm{c}_{2 \mathrm{j}}, \quad \mathrm{j}=1,2, \ldots \ldots, \mathrm{m}+\mathrm{n}$,

$\Delta \mathrm{l}_{2}{ }^{1 \mathrm{j}}=\mathrm{c}_{\mathrm{B} 3} \mathrm{x}_{\mathrm{j}}-\mathrm{c}_{3 \mathrm{j},}, \quad \Delta \mathrm{l}_{2}{ }^{2 \mathrm{j}}=\mathrm{c}_{\mathrm{B} 4} \mathrm{x}_{\mathrm{j}}-\mathrm{c}_{4 \mathrm{j}}$

And $\Delta \zeta^{1 \mathrm{j}}=\mathrm{f}_{2}(\mathrm{x}) \Delta \mathrm{l}_{1}{ }^{1 \mathrm{j}}-\mathrm{f}_{1}(\mathrm{x}) \Delta \mathrm{l}_{1}{ }^{2 \mathrm{j}}$

$\Delta \zeta^{2 \mathrm{j}}=\mathrm{g}_{2}(\mathrm{x}) \Delta \mathrm{l}_{2}{ }^{1 \mathrm{j}}-\mathrm{g}_{1}(\mathrm{x}) \Delta \mathrm{l}_{2}^{2 \mathrm{j}}$

Minimum ratio $=\min \left(\mathrm{x}_{\mathrm{Bi}} / \mathrm{x}_{\mathrm{ir}}, \mathrm{x}_{\mathrm{ir}}>0\right)$ for outgoing vector

Finally we find out:

For problem (3) $\begin{cases}\rho_{\mathrm{j}}=\mathrm{g}(\mathrm{x}) \Delta \zeta^{1 \mathrm{j}}-\mathrm{f}(\mathrm{x}) \Delta \zeta^{2 \mathrm{j}} \\ \Omega_{3 \mathrm{j}}=\frac{\rho \mathrm{j}}{\sum \mathrm{xi}}, & \text { where } \sum \mathrm{x}_{I}(>0) \text { is the sum of basic variables in running iterative } \\ \text { table to the corresponding column. }\end{cases}$

In the every iteration $c_{1 j}, c_{2 j}, c_{3 j}$ and $c_{4 j}$, are the coefficients of the basic and non basic variables and $c_{B 1}, c_{B 2}, c_{B 3}$, and $c_{B 4}$ are the coefficients of the basic variables in the objective function of the problem (5).

Step4. Obtain an optimal solution of the problem in above mentioned rules by using new technique for determine the basic vector by choosing most negative value of $\Omega_{3 j}$ (defined as above) and corresponding vector will enter into the basic and Minimum ratio $=\min \left(\mathrm{x}_{\mathrm{Bi}} / \mathrm{x}_{\mathrm{ir}}, \mathrm{x}_{\mathrm{ir}}>0\right)$ for outgoing vector in simplex processing .

Step5. If all $\rho_{j} \geq 0$ and $\Omega_{3 j} \geq 0$ then the optimum solution obtain and if not then go to step 4 and check the obtain solution for optimality. Thus the solution can be improved until all $\rho_{j} \geq 0$ and $\Omega_{3 j} \geq 0$ in simplex routine, the solution become optimal and process terminates.

Numerical example (2) [B.K. Abdulrahim, 2013]

$$
\begin{array}{r}
\operatorname{Maximize} \Phi(\mathrm{x})=\left(\mathrm{x}_{2}+1\right)\left(\mathrm{x}_{1}+\mathrm{x}_{2}+3\right) /\left(\mathrm{x}_{1}+4\right)\left(\mathrm{x}_{1}+\mathrm{x}_{2}+2\right) \\
\text { s. t. }-\mathrm{x}_{1}+\mathrm{x}_{2} \leq 1 \\
\mathrm{x}_{2} \leq 2 \\
\mathrm{x}_{1}+2 \mathrm{x}_{2} \leq 7 \\
\mathrm{x}_{1} \leq 5 \\
\mathrm{x}_{1}, \mathrm{x}_{2} \geq 0
\end{array}
$$

Using the same above procedure we can solve this problem and find out the optimal solution $\mathrm{x}_{1}=1, \mathrm{x}_{2}=2$ and $\Phi(\mathrm{x})=18 / 25$. 


\section{Conclusion}

In this paper new approach is based on the iterative procedure of simplex techniques. Sometimes this approach involves less or at the most an equal number of iteration as compared to computational procedure for solving other quadratic program which is very useful to developing theory of the linear factorized quadratic optimization and quadratic fractional optimization Here we observed that the optimal solution obtained in this paper by this approach, similar to simplex technique procedure is completely identical with that of the other methods which are laborious and time consuming. Hence this technique gives efficiency in result as compared to other method in less iteration.

\section{References}

[1]. Abdulrahim B. K. (2013), Solving Quadratic Fractional Programming Problem via Feasible Direction Development and Modified Simplex Method. Journal of Zankoy sulaimani- part A (JZS-A), 15(2), pp 45-52.

[2]. Fukushima M. and etc. all (2008), Quadratic Fractional Programming Problems with Quadratic Constraints, Department of Applied Mathematics and Physics, Graduate School of Informatics, Kyoto University.

[3]. Hasan M.B. (2012), A technique for solving special type quadratic programming problems, Dhaka university j. sci. 60(2) pp-209-215.

[4]. Khobragade N. W. and ets all (2012), alternative approach to wolfe's modified simplex method for quadratic programming, Int. J. Latest Trend Math vol.-2(1) pp-19-24.

[5]. R. Enkhbat and etc. all (2011), A method for fractional programming, International Journal of Pure and Applied Mathematics, Volume 73 No. 1, pp.93-99.

[6]. Sharma, S. D. (1994), Non-linear and dynamic programming, Kedar Nath Ram Nath \& CO., Meerut, India.

[7]. Swarup Kanti, gupta P. K. and man mohan (2008), Tracts in operational research, Sultan chand \& Sons Educational publisher, New Delhi (India)

[8]. Vankova M. (2004), Algorithms for solution of the quadratic programming problem, university of Port Elizabeth. 